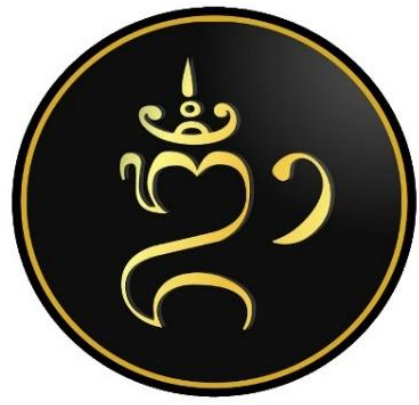

E-ISSN: $2722-8576$

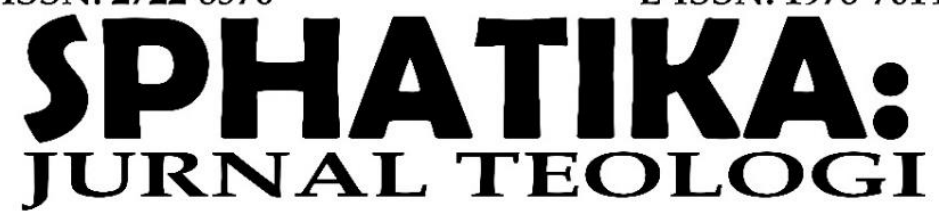

UNIVERSITAS HINDU NEGERI

I GUSTI BAGUS SUGRIWA DENPASAR

VOLUME 12 NOMOR 2, SEPTEMBER 2021

\title{
KAJIAN BHAGAVAD GITTA TERHADAP MAKNA PRASADAM BAGI MASYARAKAT HINDU DI BALI
}

\author{
Ida Bagus Subrahmaniam Saitya1, Ni Gusti Ayu Nyoman Meilani ${ }^{2}$ \\ 1,2Universitas Hindu Negeri I Gusti Bagus Sugriwa Denpasar \\ 1tugusbramsaitya@uhnsugriwa.ac.id
}

\begin{tabular}{l}
\hline Keywords: \\
Bhagavad Gìtā; \\
prasadam
\end{tabular}

Kata kunci:

Bhagavad Gìtā;

prasadam

\begin{abstract}
Prasadam in Hinduism is a term in Sanskrit which means God's gift, which is the result or remnant of an offering to Ida Sang Hyang Widhi Wasa who has been purified. In the Hindu community in Bali the term lungura/surudan is better known than the term prasadam. Related to the phenomenon of prasadam, after being investigated, it turns out that the term lunguran/surudan indicates the strata or class of a dish that starts with the offering (bebanten), complete with food, after being offered, the contents of the bakuten turn into lunguran/surudan, which is ready to be enjoyed as a form of grace from Ida Sang Hyang Widhi or Ida Bhatara-Bhatari who has been presented with a sincere heart and has sacred values and is meaningful as prasadham (holy dish). The Bhagavad Gita states that, those who eat holy food after going through an offering or sacrifice will attain eternal Brahman (God). So there is no reason to think, whether to accept or desire to refuse the blessings of the blessing of Prasadam, because it has previously been offered as a sacred dish for Ida Sang Hyang Widhi Wasa and His manifestations.
\end{abstract}

\section{Abstrak}

Prasadam dalam ajaran agama Hindu merupakan istilah dalam bahasa Sanskerta yang artinya anugrah Tuhan, yang berupa hasil atau sisa dari persembahan kepada Ida Sang Hyang Widhi Wasa yang telah disucikan. Pada masyarakat Hindu di Bali istilah lungsura/surudan lebih dikenal dibandingkan dengan istilah prasadam. Terkait dengan fenomena prasadam setelah ditelisik, ternyata istilah lungsuran/surudan menunjukkan strata atau kelas suatu hidangan yang bermula dari haturan 


persembahan (bebanten), lengkap dengan makanan, usai
dipersembahkan, isi bebanten itu berubah menjadi
lungsuran/surudan, yang siap dinikmati sebagai wujud anugrah
dari Ida Sang Hyang Widhi atau Ida Bhatara-Bhatari yang sudah
dipersembahkan dengan hati yang tulus ikhlas dan benilai suci
serta bermakna sebagai prasadham (hidangan suci). Kitab suci
Bhagavad Gita menyatakan bahwa, mereka yang makan
makanan suci setelah melalui suatu persembahan atau
pengorbanan akan mencapai Brahman yang abadi (Tuhan).
Sehingga tidak ada alasan untuk berpikir, apakah hendak
menerima atau berhasrat menolak nikmat berkah anugrah
prasadam, sebab sebelumnya telah dipersembahkan sebagai
sajian suci bagi Ida Sang Hyang Widhi Wasa beserta manifestasi-
Nya.

\section{PENDAHULUAN}

Masyarakat Hindu di Bali lebih mengenal istilah lungsuran/surudan dibandingkan dengan prasadam, dimana tiap kali sehabis melakukan persembahyangan dalam suatu upacara, pasti selalu disuguhkan sisa persembahan yang disebut dengan "lungsuran" yang memiliki arti sisa persembahan. Namun, sejak mengenal saudara-saudara umat Hindu dari India mulai dikenal istilah "prasadam" yang maknanya lebih diperjelas sebagai sesuatu yang sudah disucikan lewat upacara persembahan kepada Ida Sang Hyang Widhi. Istilah prasadam dan lungsuran, dimaksudkan mempunyai makna yang sama, akan tetapi dalam praktiknya tidak sama.

Lungsuran merupakan istilah yang dikenal lebih dulu pengertiannya sudahkesana kemari, sehingga pakain bekas, makanan bekas, dan lainnya yang bukan hasil persembahan kepada Hyang Widhi bisa diberi arti sebagai lungsuran. Sedangkan istilah prasadam yang muncul kemudian seperti memurnikan kembali makna persembahan kepada Ida Sang Hyang Widhi Wasa ini menjadi lebih spesifik sehingga maknanya bisa dipahami lebih dalam, dengan demikian umat menjadi faham, bahwa dengan memakan prasadam, maka kita telah menikmati makanan yang sudah disucikan. Berbeda sekali dengan istilah lungsuran, yang oleh sebagian masyarakat telah diartikan keliru sejalan dengan kelirunyapengertian akan kesetaraan manusia.

Fenomena prasadam atau lungsuran yang terjadi pada masyarakat Bali, terkait dengan adanya masyarakat yang tidak mau mengkonsumsi lungsuran dari persembahan di Pura keluarga, kawitan, sanggah, serta panti orang lain, walaupun itu teman baiknya, namun karena temannya dari keluarga yang berbeda(soroh/trah/wangsa). Sehingga sisa persembahan 
yang sudah disucikan ini menjadi dikalahkan oleh pemahaman keliru karena berbeda soroh/trah/wangsa yang dibedabedakan struktur klas sosialnya secara vertikal (tinggirendah/atas- bawah).

Persembahan dalam kitab suci Bhagavad Gìtā dijelaskan bahwa yajnayang dilakukan oleh umat Hindu memiliki tujuan yang utama, didalamnya terkandung nilai-nilai universal untuk memenuhi tujuan yang sesuai dengan doktrin "Mokshartam Jagadhitaya Ca Iti Dharma" dan "Catur Purusa Artha". Umat Hindu yang melakukan yajna akan terbebaskan dari ikatan dosa. Dijelaskan dalam Bhagavad Gìtā bahwa, orang-orang yang baik memakan apa yang tersisa dari yajna mereka itu akan terlepas dari segala dosa. Sehingga dengan melakukan persembahan (yajna), serta mengkonsumsi hidangan hasil dari persembahan yang telah disucikan dengan didasari hati tulus iklas, juga dapat membebaskan diri dari seseorang ikatan hukum karma.

Terkait dengan uraian tersebut, menarik minat peneliti untuk melakukan analisis mengenai pengertian prasadam, fenomena prasadam yang terjadi di Bali, dan pandangan Bhagavad Gìtā tentang hakikat prasadam, dengan mengangkat masalah mengenai makna prasadam dalam masyarakat hindu di Bali menurut pandangan Bhagavad Gitā. Sehingga dengan dilakukannya penelitian ini diharapkan bisa menjernihkan kekeliruan, bahkan tidak terbatas pada makanan saja, apapun hasil persembahan adalah prasadam, seperti: sisa canang, bambu, daun kelapa, kelapa, dan lain sebagainya adalah prasadam. Sisa persembahan yang selama ini bagi umat Hindu kurang berharga hanya berupa sampah, bisa diberi pengertian prasadam sehingga lebih bermakna, dengan penajaman makna dari lungsuran menjadi prasadam.

\section{METODE}

Penelitian ini menggunakan metode kualitatif, dengan menggunakan analisa deskriptif kualitatif, dimana seting tempat kondisi dan situasinya sebagai data langsung, menggunakan pendekatan fenomenologis. Sumber data dalam penelitian ini adalah buku, artikel, literatur dan arsip-arsip yang berisi informasi mengenai makna Prasadam. Teknik pengumpulan data menggunakan studi kepustakaan. Instrumen pengumpulan data berupa kertas, alat tulis, laptop, dan teknik analisis data dalam penelitian ini menggunakan deskritif kualitatif. Data yang telah terkumpul dianalisis dengan cara reduksi data, klasifikasi data, display data, dan memberikan interpretasi dan memberikan kesimpulan. Berdasarkan uraian tersebut penyajian data dilakukan dalam bentuk deskriptif yaitu data diuraikan dalam kalimat-kalimat sehingga membentuk suatu pengertian yang berhubungan dengan masalah 
yang diteliti.

\section{PEMBAHASAN}

\section{Pengertian Prasadam}

Prasadam adalah Bahasa Sanskerta yang artinya anugrah Tuhan. Menurut Wikipedia dalam Pashaura Singh (2014) menyatakan bahwa prasāda, dengan variasi dieja sebagai Prasādam, Prasād dan Prasāda, adalah bahan makanan vegetarian yang merupakan persembahan religius baik dalam agama Hindu maupun Sikh, biasanya dikonsumsi oleh umat setelah melakukan persembahan dan persembahyangan.

Wikipedia dalam Natu (1987) menyatakan prasada berasal dari kata kerja prasād yang terdiri dari kata kerja (sedih, duduk, berdiam) yang diawali dengan (pra - sebelum, sebelum, di depan) dan digunakan sebagai kata kerja terbatas (prasìdati - tinggal, memimpin, menyenangkan atau nikmat dll). Prasada atau prasadam secara harfiah berarti hadiah yang murah hati. Ini menunjukkan apa saja, biasanya makanan yang dapat dimakan, yang pertama kali dipersembahkan kepada dewa, orang suci, Guru Sempurna atau seorang avatar, dan kemudian didistribusikan dalam nama-Nya kepada pengikut mereka atau orang lain sebagai pertanda baik.

Prasadam ini tidak sama dengan "bekas (lungsuran)" dalam bahasa Bali, disini artinya adalah anugrah Tuhan yang suci. Mungkin dahulu orang Bali tidak mengenal bahasa lain maka secara sehari-hari disebut lungsuran. Jika disimak secara hati orang Bali menyebut lungsuran dari Pura dengan lungsuran (bekas) orang, dengan perasaan hati yang berbeda. Istilah prasadam dan lungsuran dimaksudkan mempunyai makna yang sama namun dalam praktiknya tidak sama. Lungsuran merupakan istilah yang dikenal lebih dulu pengertiannya sudah kesana kemari, sehingga pakain bekas, makanan bekas, dan lainnya yang bukan hasil persembahan kepada Hyang Widhi bisa diberi arti sebagai lungsuran. Menurut Kamus Besar Bahasa Indonesia, arti kata lungsuran adalah pakaian bekas (barang lama dan sebagainya). Lungsuran berasal dari kata dasar lungsur. Lungsuranmemiliki arti dalam kelas nomina atau kata benda sehingga lungsuran dapat menyatakan nama dari seseorang, tempat, atau semua benda dan segala yang dibendakan.

Pengertian terkait dengan istilah prasadam yang muncul kemudian seperti memurnikan kembali makna persembahan kepada Ida Sang Hyang Widhi Wasa, menjadi lebih spesifik sehingga maknanya bisa dipahami lebih dalam, dengan demikian umat menjadi paham, bahwa dengan memakan prasadam, maka kita telah menikmati makanan yang sudah 
disucikan melalui suatu proses upacara. Berbeda sekali dengan istilah lungsuran, yang oleh sebagian masyarakat telah diartikan keliru sejalan dengan kelirunya pengertian akan kesetaraan manusia.

\section{Fenomena Prasadam di Bali}

Prasadam selalu menjadi polemik di dalam masyarakat Bali, karena prasadam yang harusnya dinikmati, malah menjadi tumpukan sampah yang berdampak pada masalah lingkungan. Terkait dengan sisa-sisa upakara baik itu dalam skala rumah tangga ataupun dalam skala besar seperti Panca Bali Krama dibuang seenaknya seperti sampah, padahal sampah tersebut sesungguhnya adalahprasadam (lungsuran/surudan).

Pada hari Raya Galungan dan Kuningan, seluruh umat Hindu menghaturkan persembahan kepada Ida Sang Hyang Widhi Wasa dan setelah persembahan itu dihaturkan, harus dimakan. Tuhan, yang tak berwujud tentulah tak akan "memakan" persembahan itu, dan jika pun ada istilah "sisa makanan", maka tak lain artinya "makanan yang sudah diberkahi". Hal ini bisa terjadi karena sejak Sugihan (lima hari sebelum Galungan) sudah menghaturkan sesajen. Kegiatan itu hampir tak terputus sampai Kuningan sekarang ini. Jika diberikan ke tetangga problemanya sama juga, tetangga juga banyak menyisakan prasadam. Dulu ketika ekonomi belum sebaik sekarang, leluhur kita memang punya tradisi yang disebut ngejot. Jika satu keluarga punya hajatan maka prasadam dari sesajen itu dibagi-bagikan kepada tetangga. Sekarang pada saat ekonomi maju dan semua keluarga mampu menyelenggarakan yadnya yang sama besarnya, maka prasadam pun menumpuk. Bayangkan betapa banyak prasadam dari sesajen itu. Padahal dalam kitab suci Hindu, prasadam adalah makanan yang sattwik, makanan utama, karena telah dipersembahan kepada Tuhan atau pun kepada para leluhur yang biasa disebut Ida Benthara atau Dewata Dewati.

Fenomena upacara mecaru yang dilakukan umat Hindu di Bali, ada yang mengartikan persembahan kepada Bhuta Kala sehingga jangankan prasadam, kembang saat sembahyang saja tidak boleh ditempatkan di telinga/kepala (suntingang), disisi lain ada yang mengartikan caru yang memiliki arti harmonis, seimbang adalah permohonan kepada Ida Sang Hyang Widhi untuk keseimbanganalam, sehingga sisa persembahyangan jelas adalah prasadam.

Terkait dengan fenomena prasadam lainnya yang terjadi di masyarakat Hindu di Bali, dimana sisa persembahyangan dari Pura keluarga (leluhur orang lain), sebagian masyarakat feodal mengatakan ini beda leluhur sehingga tidak maumakan sisa persembahyangan itu, artinya mereka menganggap ini bukanprasadam. Disisi lain para penganut sudut pandang tattwa mengartikan orangyang sudah meninggal karena, panca maha bhuta sudah lebur lewat 
upacarangaben, dan badan astral (badan halus) sudah lebur dengan Memukur (Atmawedana) sehingga tinggal atma yang merupakan bagian dari Paramatma dandilinggihkan di kemulan sebagai Dewa Hyang, maka sesungguhnya sisa persembahan ini adalah prasadam.

Perbedaan makna dari prasadam (lungsuran/surudan), lain pula paridan, apalagi carikan. Kalau paridan berkaitan dengan persembahan bebanten yangsetelah di parid (seperti natab) hanya boleh dinikmati oleh yang memarid (boleh juga untuk saudara muda/adiknya), seperti dalam contoh marid otonan. Sedangkan apa yang disebut carikan, konotasinya lebih kepada sesuatu, terutama yang berhubungan dengan sajian/hidangan/makanan yang masuk katagori "sisa" (barang bekas/laad-laadan), sehingga amat jarang mau diterima apalagi dinikmati orang lain.

Setelah ditelusuri lebih dalam melalui realita yang ada dimasyarakat, ternyata istilah prasadam (lungsuran/surudan) menunjukkan strata atau kelassuatu hidangan yang bermula dari haturan kepada Ida Sang Hyang Widhi yang berupa persembahan (banten) yang telah disucikan, lengkap dengan makanan(nasi/ketupat, ikan/daging, buah, dan jajanan). Setelah selesai dipersembahkan, isi bebanten itu berubah menjadi prasadam, yang siap dinikmati sebagai wujud anugrah dari Ida Sang Hyang Widhi atau Ida Bhatara-Bhatari. Terkait dengan persoalan mau tidaknya seorang umat menerima dan menikmatinya sangat tergantung pada suatu hal, yang biasanya dikaitkan dengan kepada siapa haturan bebanten itu dipersembahkan, di Pura dengan status apa (soroh/trah/wangsa) dan siapa yang menghaturkannya. Sehingga sisa persembahan yang sudah disucikan ini menjadi dikalahkan oleh pemahaman keliru karena berbeda soroh/trah/wangsayang dibedabedakan struktur klas sosialnya.

\section{Prasadam dalam Pandangan Bhagavad Gīt $\bar{a}$}

Prasadam dalam pandangan Bhagavad Gìtā merupakan pesembahan suci yang merupakan anungrah Tuhan. Hukum Tri Kona (utpeti-sthiti-pralina) adalah sistem daur ulang kehidupan. Apa yang tiada menjadi ada, lalu terpelihara untuk akhirnya kembali sima. Begitupun dengan aktivitas yadnya, di utpeti dulu menjadibanten, di sthiti menjadi haturan bhakti, sampai akhirnya menjadi pasuecan/paican Ida Bhatara. Sari pati hasil pertemuan bhakti umat kalawansueca Widhi/Ida Bhatara-Bhatari itulah kemudian lumrah disebut lungsuran atau surudan, yang dalam bahasa Sanskrit dinaikkan derajat maknanya menjadi prasadham (menikmati sajian yang telah disucikan).

Jika bebanten dihaturkan kehadapan Hyang Widhi di ajeng palinggih Padmasana, atau setidaknya di Pura dengan status Kahyangan Jagat, hingga Kahyangan Tiga, sepertinya umat 
dari kalangan manapun akan bisa menerima dan menikmatinya. Namun tak dapat dimungkiri, adakalanya dikait-kaitkan lagi dengan siapa yang menghaturkannya. Bila haturan bebantennya berasal dari kelompok yang dianggap tidak sewangsa/sesoroh, apalagi tidak menyama, seringkali ditolak, dan tak akan mau dinikmati lungsuran/surudannya.

Apalagi kalau haturan bebantennya berasal dari persembahan kehadapan Ida Bhatara-Bhatari kawitan/leluhur; lalu dihubungkan lagi dengan derajat (tinggi-rendah) posisi dalam strata wangsa/soroh, meski lungsuran/surudannya terbilang mengundang selera, dipastikan akan ditolak dengan berbagai alasan. Tak dinyana untuk urusan lungsuran/surudan sebagai bukti anugrah Hyang Widhi/Ida Bhatara-Bhatari yang sudah meraga suci/sunya, umat (damuh/panjak) justru merasa diri "lebih suci" hinga harus memilah dan memilih lungsuran/surudan mana yang boleh/mau diterima dan dinikmati.

Inilah realita kehidupan sosial keagamaan umat Hindu yang memang tak lepas dari pengaruh bius feodalisme. Meski konsep Hindu dengan lantang didengungkan dalam jargon sarwam idham khalu Brahman (semua makhluk adalah ciptaan Tuhan), sehingga terealisasi menjadi wasudewa kuthum bhakam (semua makhluk adalah bersaudara), tetapi kenyataannya tidak dapat dipungkiri bahwa ada semacam klasifikasi/klusterisasi dalam masyarakat Hindu (Bali). Rujukan konsepnya sebenarnya berasal dari kitab suci Bhagawad Gìtā yang menyatakan:

cāturvarṇyaṃ mayā ș̣̦țam

guṇa-karma-vibhāgaśaḥ,

tasya kartāramapi māṃ

viddhyakartāramavyayam

(Bhagavad Gìtā IV.13)

Terjemahannya:

Caturvarna (empat tananan masyarakat) adalah ciptaan-Ku menurut pembagian kwalitas dan kerja; tetapi ketauilah bahwa walaupun Aku penciptanya, Aku tak berbuat dan merbah diri-Ku (Pudja, 2013:115).

Berdasarkan kutipan sloka Bhagavad Gìtā tersebut dapat dipahami bahwa Catur Warna yang menggolongkan manusia berdasarkan guna (sifat) dan karma (kewajiban), sehingga berposisi sederajat. Namun dalam perkembangannya, suka tidak suka, terima tidak terima, bermetamorfosa menjadi Catur Wangsa (menurut keturunan: wangsa/trah/soroh), yang pada kenyataannya kemudian, masyarakat Hindu (Bali) dibedabedakan struktur klas sosialnya secara vertikal (tinggi rendah/ atas-bawah). Bahkan dari keempat kelompok wangsa itu, diklasisfikasi lebih eksklusif lagi menjadi dua golongan besar, yang satu dinamakan Tri 
Wangsa (Brahmana, Ksatria, Wesia) dan satunya lagi disebut Jaba (di luar wangsa: Sudra). Kalau sudah begini penjelasannya hal-hal yang berhubungan dengan lungsuran/surudan bisa bertambah ribet dan ruwet. Padahal pokok persoalannya sangat sederhana, menyangkut urusan menikmati, tepatnya memakan haturan bebanten yang sudah dipersembahkan dengan hati yang tulus ikhlas dan benilai suci sebagai waranugraha Ida Sang Hyang Widhi Wasa/Ida Bhatara-Bhatari sertabermakna sebagai prasadham (hidangan suci).

Persoalan istilah, sejatinya yang disebut prasadham (lungsuran/surudan) adalah utama karena berasal dari suatu persembahan suci untuk mencapai kelepasan yang merupakan akhir dari tujuan agama Hindu yaitu Moksa. Jadi beryajna merupakan jalan untuk mencapai Brahman yang merupakan suatu tujuan yang amat mulia dengan membebaskan diri dari ikatan-ikatan dunia. Mereka yangmemakan makanan suci dari sisa-sisa yajna akan mencapai Brahman, sebagaimana disebutkan dalam kitab suci Bhagawad Gītā yang menyatakan:

Yajna-sistamrta-bhujo

yanti brahma sanatana,

nayam loko'sty ayajnasya

kuto 'nyah kuru-sattama

(Bhagavad Gītā IV.31)

Terjemahannya:

Mereka yang makan sisa per-sembahan, sebagai amrta, mencapai Brahman yang kekal abadi, dunia ini bukan bagi yang tidak beryajña apapula dunia yang lain, wahai Arjuna (Pudja, 2013:126).

Berdasarkan kutipan sloka Bhagavad Gītā tersebut dapat dipahami bahwa, sebenarnya tidak ada alasan untuk berpikir, apakah hendak menerima atau berhasrat menolak nikmat berkah anugrah lungsuran/surudan, sebab sebelumnya telah dipersembahkan sebagai sajian suci bagi Ida Sang Hyang Widhi Wasa beserta manifestasinya, termasuk Ida Bhatara-Bhatari, kecuali mungkin yangdilekatkan label kawitan/leluhur yang memang tak pernah lepas dari embel-embel wangsa/soroh, bagi masyarakat Bali (Hindu) tradisional-konservatif memang masih dilakoni dengan fanatik.

Namun bagi generasi mileneal yang begitu akrab bergaul dengan dunia kontemporer, fanatisme terhadap prasadam (lungsuran/surudan) sudah semakin mencair, karena dianggap tidak masalah menikmati berkah yang berasal darisajian persembahan, karena sudah menjelma menjadi suguhan berenergi, baikuntuk asupan gizi jasmani maupun rohani, yang tentunya bersifat suci (sattwika), seperti ditegaskan di dalam kitab Bhagawad Gìtā yang menyatakan: 
aphalākanikșibhir yajño

vidhi-drșțo ya ijyate,

yaștavyam eveti manah

samādhāya sa sāttvikah.

(Bhagavad Gìtā XVII.11)

Terjemahannya:

Yajña yang dipersembahkan sesuai dengan aturan kitab suci oleh mereka yang tidak mengharapkan ganjaran dan sangat percaya bahwa itu merupakan kewajibanyang harus dilakukan, merupakan yadnya sattwika (Pudja, 1981: 392).

Berdasarkan kutipan sloka Bhagavad Gìtā tersebut dapat dipahami bahwa pelaksanaan yajña berdasarkan kualitasnya yang satvam. Korban suci yang dilakukan oleh seseorang sangat tergantung dari keikhlasannya, bukan atas kemewahan atau mahalnya pelaksanaan korban suci tersebut. Dengan demikian, prasadam yang dinikmatipun merupakan berkah anugrah dari Tuhan yang bersifatsattwika, sebagai pondasi bagi usaha membangun karakteristik daiwi sampat (sifatkedewataan) yang sangat diperlukan dalam meruntuhkan kuasa asuri sampat (watak keraksasaan) yang kini tampak kian eksis di tengah kehidupan multi krisis seperti sekarang ini.

Ada suatu renungan bagi seluruh umat manusia, bahwa dengan mempersembahkan diri sendiri kepada Ida Sang Hyang Widhi dengan menjaga kesucian (Tri Kaya Parisudha), melakukan fungsi sesuai dengan "Guna (bakat)" dan "Karma (laku/perbuatan) sesuai dengan ajaran Catur Warna, juga melakukan tapa-brata-yoga-samadi (pengendalian diri), dan bentuk pesucian lainnya, sesungguhnya kita telah menyiapkan diri menjadi prasadam bagi orang lain.

Bahwa perlu dipahami, segala hal yang ada di semesta ini merupakanyajna yang dilakukan oleh Ida Sang Hyang Widhi Wasa, yang kemudian kita kenal Beliau sebagai Sang Pencipta. Sebagai insan yang diciptakan melalui yajna, kita kemudian diwajibkan melakukan yajna, agar Cakra Dharma kehidupan ini berlangsung terus menerus. Segala hal tanpa kecuali yang kita nikmati wajib hukumnya kita haturkan kepada satu-satunya kepada Sang Pemilik yakni Ida SangHyang Widhi, dan setelahnya baru layak kita nikmati, agar kita tidak bertindak sebagai seorang pencuri.

\section{PENUTUP}

Prasadam adalah Bahasa Sanskerta yang artinya anugrah Tuhan, merupakan suatu persembahan yang dihaturkan atau dipersembahkan kepada Tuhan yang didasari atas hati yang tulus dan ikhlas, sehingga makan dari hasil persembahan yang dimakan tersebut adalah 
anugerah dari Tuhan Yang Maha Esa.Namun tidak dapat dipungkiri, adakalanya prasadam dikait-kaitkan lagi dengan siapa yang menghaturkannya. Bila haturan bebantennya berasal dari kelompok yang dianggap tidak sewangsa/sesoroh, apalagi tidak menyama, seringkali ditolak, dan tak akan mau dinikmati prasadam. Sehingga sisa atau hasil persembahan yang sudah disucikan ini menjadi dikalahkan oleh pemahaman keliru karena berbeda soroh/trah/wangsa yang dibedabedakan struktur klas sosialnya.

Dalam Bhagavad Gìtā disebutkan prasadham adalah yang utama, karena berasal dari suatu persembahan suci untuk mencapai kelepasan yang merupakan akhir dari tujuan agama Hindu yaitu Moksa. Jadi beryajna merupakan jalan untuk mencapai Brahman yang merupakan suatu tujuan yang amat mulia dengan membebaskan diri dari ikatan-ikatan dunia. Mereka yang memakan makanan suci dari sisa-sisa yajna akan mencapai Brahman. Sehingga tidak ada alasan untuk berpikir, apakah hendak menerima atau berhasrat menolak nikmat berkah anugrah Tuhan yang berupa prasadam, sebab sebelumnya telah dipersembahkan sebagai sajian suci bagi Ida Sang Hyang Widhi Wasa beserta manifestasi-Nya, termasuk Ida Bhatara-Bhatari.

\section{DAFTAR PUSTAKA}

Djelantik. 2016. Prasadam. https://djelantik.wordpress.com/2016/12/13/prasadam/ diakses 26 Desember 2020.

Pudja, G. 2013. Bhagavad Gìtā (Pancama Weda). Surabaya: Pāramita.

Natu, Bal, Glimpses of the God-Man, Meher Baba, Sheriar Press, 1987. https://en.m.wikipedia.org/wiki/Prasāda diakses 25 Desember 2020.

Pashaura Singh, Louis E. Fenech, 2014, The Oxford Handbook of Sikh Studies. https:/ / en.m.wikipedia.org/wiki/Prasāda diakses 25 Desember 2020.

Sudarma, I Wayan. https://phdi.or.id/artikel/lungsuran-vs-prasadam diakses 26 Desember 2020.

Arti Kata Lungsuran di Kamus Besar Bahasa Indonesia (KBBI) https://lektur.id/artilungsuran/ diakses 25 Desember 2020.

Prasadam Adalah Anugrah Bukan 2011. http://agusmuliana.blogspot.com/2011/12/prasadam-adalah-anugrah- bukansampah.html diakses 26 Desember 2020 